\title{
Derin Öğrenme Algoritmalarını Kullanarak Görüntüden Cinsiyet Tahmini
}

\author{
Gül GÜNDÜZ1, (iD İsmail Hakkı CEDİMOĞLU² \\ ${ }^{1}$ Gül GÜNDÜZ, Sakarya Üniversitesi; Mühendislik Fakültesi; Endüstri Mühendisliği Bölümü; \\ gul.gunduz@ogr.sakarya.edu.tr \\ ${ }^{2}$ İsmail Hakkı CEDİMOĞLU, Sakarya Üniversitesi; Bilgisayar ve Bilişim Bilimleri Fakültesi; Bilişim Sistemleri \\ Mühendisliği Bölümü; cedim@sakarya.edu.tr
}

Received: 25/01/2019; Revision; 04/03/2019 Accepted; 14/03/2019 Published online; 25/04/2019

\section{Öz}

Büyük verilerin büyük hızlarla işlendiği çağımızda milyarlarca veriden farklı parametreler çıkararak çeşitli problemlerin çözümüne kolaylık getirmek için derin öğrenme algoritmaları kullanılmaktadır. Bu çalışmada, mevcut veri setlerinde bulunan kadın, erkek, yaşlı, genç, çocuk, bebek fotoğraflarının derin öğrenme algoritmaları ile cinsiyetlerini tespit etmek amaçlanmıştır. Bu tahminleme algoritmasını gerçekleştirmek için çeşitli derin öğrenme kütüphanelerinden faydalanılmış ve derin öğrenme modellerinden Alex Net ve VGG-16 ile yeni geliştirilen bir modelin diğer modellerle kıyaslanması yapılmıştır.

Uygulamada kullanılan veri seti, kadın ve erkek fotoğraflarından oluşturulmuştur. Her fotoğraf ise kişi cinsiyetine ve yaşına göre etiketlendirilmiştir. Bu veri seti, 3170 eğitim verisi ile 318 test verisi içermektedir. Çalıştırılan üç farklı model sonuçları karşılaştırılmıştır. Makalede, derin öğrenme algoritmalarını kullanarak cinsiyet tahmini yapılması ayrıntılı bir şekilde incelenmiş ve yapılacak olan literatür çalışmalarına yol gösterilmesi, katkı sağlanması hedeflenmiştir.

Anahtar kelimeler: Derin öğrenme, derin öğrenme algoritmaları, cinsiyet tahmini

\section{Gender Estimation with Image by Using Deep Learning Algorithms}

\begin{abstract}
In our age, where big data is processed at great speeds, deep learning algorithms are used to facilitate the solution of various problems by extracting different parameters from billions of data. In this study, it is aimed to determine the genders of female, male, old, young, child and baby photographs in the existing data sets with deep learning algorithms. To realize this prediction algorithm, various deep learning libraries were used and a new model with deep learning models Alex Net and VGG-16 was compared.

The data set used in the application is composed of male and female images. Each image is labeled according to the gender and age of the person. This data set includes 3170 training data and 318 test data. The results of three different models were compared. The article explains in detail how to make a gender prediction using deep learning algorithms and aims to contribute to the literature studies.
\end{abstract}

Keywords: Deep Learning, deep learning algorithms, gender estimation

\section{Giriş}

Sosyal bir varlık olan insanlar, çevreyle etkileşim içindedir. Cinsiyet ise sosyal etkileşimlerde temel rol oynayan özelliklerden biridir. Cinsiyet farklılığına göre hitabetin değişmesi, bazı kültürlerde cinsiyet ögelerine göre dilbilgisi kurallarının değişmesi, kişinin cinsiyetine göre selamlama özelliklerinin farklılık göstermesi bu sosyal etkileşimlerden sadece birkaçıdır.

Son yıllarda cinsiyet tahmini uygulamaları çeşitli teknolojilerle karşımıza çıkmaktadır. En bilinen örneklerinden biri olan Microsoft'un fotoğraflar üzerinden yaş ve cinsiyet tahmini yapan internet sitesi "How Old Do I Look?" oldukça popüler olarak kullanılmaktadır. Fotoğraflardaki yüzleri algılayan, kişilerin cinsiyetini tahmin eden ve yaşını söyleyen site eğlence amaçlı kullanılmaktadır [1]. Bir diğer önemli örnek ise; Xiaomi Mi 6'nın ön yüzünde 8 mega piksel çözünürlüklü, otomatik yüz güzelleştirme filtreli ve yapay zekâyı kullanarak cinsiyet ve yaş tahmini yapabilen bir kamerasının bulunuyor olmasıdır 
[2]. Bu uygulama örnekleri çoğaltılabilir ve sosyal medya kullanan toplum yapısının artmasıyla yaş ve cinsiyet tahminine ilginin artacağı öngörülebilir.

Bu çalışmada, büyük veri (big data) ve hayatımızı kolaylaştıran derin öğrenme ağ yapısını kullanarak, veri artırma yöntemiyle çoğaltılan sentetik verili fotoğraflardan cinsiyet tahmini yapan modeller kullanılmıştır.

Çalışmanın amacı, derin öğrenme algoritmalarını kullanarak, mağazalarda ürünlerle ilgilenen insanların, bir mağazada alışveriş yapmayı tercih eden insanların, Alışveriş merkezlerindeki müşterilerin, sosyal medya platformlarındaki kullanıcıların, siyasilerin mitinglerindeki kişilerin başta olmak üzere, görüntüleri üzerinden cinsiyet tahmini demografisini tespit etmeye yardımcı olacak bilgiler ve yöntemler sunmaktır. Aynı zamanda veri sayısı artırmanın başarıma olan etkisi vurgulanmaktadır. Bu amaçla çalışmaya uygun bir veri seti hazırlanmıştır. Veri seti kadın(female) ve erkek(male) olmak üzere 2 sınıfa ayrılmış ve her görüntü cinsiyete göre ve yaş bilgisine göre etiketlenmiştir. Veri setinde bulunan, yaşları 34-35 olan erkek resimleri ile yaşları 16-17 olan kadın resimleri şekil 1'deki gibi etiketlenerek veri seti hazırlanmıștır. Vikipedi veri setinin tamamına "https://data.vision.ee.ethz.ch/cvl/rrothe/imdb-wiki/" linkinden erişilebilir. Derin öğrenme algoritmalarından VGG-16 kullanarak yapılan bir çalışmada yaş tahminlemek için de Vikipedi veri setinden faydalanılmıştır [3].
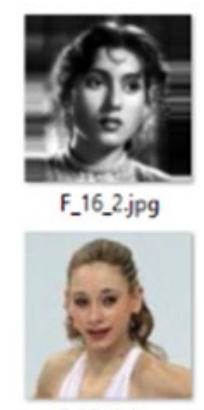

F_17_A.jpg

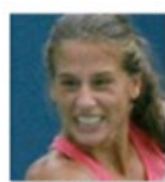

F_16_3.jpg

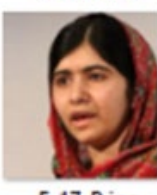

F_17_B.jpg

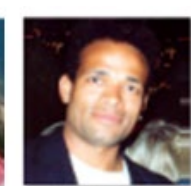

M_34_6.jpg

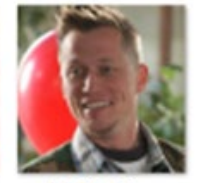

M_35_5.jpg



M_34_.j.jpg

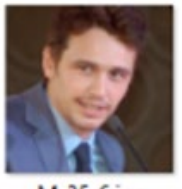

M_35_6.jpg

Şekil 1 Uygulama İçin Vikipediden Derlenen Veri Seti ve Veri Etiketleri

Uygulamanın hazırlanması için Ubuntu Linux işletim sistemi üzerinde, Python dilinde program kodları yazılıp derin öğrenmede çeşitli kütüphaneler kullanılmıştır ve cinsiyet veri setleri üzerinden gerekli tahminler yapılmıştır. Projede Python dilinin seçilme nedeni ise hızlı geliştirme olanağı ve topluluk desteğine sahip olmasıdır. Ayrıca Linux işletim sistemlerinde Python programlama dilinin kurulu olarak gelmesi de bu sebeplerden biridir. Makalenin organizasyon yapısı 4 temel bölümden oluşmaktadır. Bölüm 1'de makaleye giriş yapılmış, cinsiyet tahmini konusunun neden seçildiği üzerinde durulmuştur. Bölüm 2'de gerekli literatür araştırması yapılmıştır. Bölüm 3'te çalışmanın uygulama kısmı hakkında bilgi verilmiştir. Bölüm 4'te ise sonuçlar ve öneriler sunularak değerlendirmeler yapılmıştır.

\section{Materyal ve Method}

Derin öğrenme, bilgisayarların deneyimden ders almasını ve dünyayı kavramların hiyerarşisi açısından anlamasını sağlayan bir makine öğrenmesidir [4]. Literatürde ve uygulamada derin öğrenmenin kullanıldığg çok sayıda çalışma yapılmıştır. Doğal dil işleme, görüntü ve video işleme, biyomedikal sinyal ve görüntü işleme, nesne tanıma, robotik, kimya, reklam, finans, arama motorları, otonom araç sistemleri gibi çok çeşitli konularda derin öğrenme uygulamaları geliştirilmektedir [5]. Derin öğrenme genel olarak verinin temsilinden öğrenmeye dayanmaktadır. Bu çalışmada ele alınan cinsiyet tahmini ile ilgili akademik çalışmalar son yıllarda popülerlik kazanmıştır. Bu çalışmaların bazıları detaylı olarak incelenmiş ve yapılan çalışmanın farklılıklarının belirlenmesi için yol göstermiştir. Cinsiyet sınıflandırma için kullanılan ilk metotlardan biri, yapay sinir ağlarının az sayıda insan yüzü görüntüsünü içeren veri setiyle eğitilmesine dayanmaktadır [6]. Gil Levi ve Tal Hassner konvolüsyonel sinir ağlarını 
kullanarak yaş ve cinsiyet sınıflaması yaptığı çalışmada önemli ilerlemeler kaydetmiştir. Bu makalede, konvolüsyonel sinir ağları (CNN) kullanılarak, temsilleri öğrenerek, yüz tanımaya ilişkin performansta önemli bir artış elde edilebileceği gösterilmektedir. Bu amaçla, öğrenme verilerinin miktarı sınırlı olduğunda bile kullanılabilen basit bir kıvrımlı net mimarisi önerilmiştir. Son zamanlardaki Adience kriterlerine ilişkin yöntemi, yaş ve cinsiyet tahmini açısından değerlendiren çalışma, güncel yöntemlerden önemli ölçüde daha iyi performans gösterdiğini belirtmektedir [7]. Konvolüsyonel sinir ağlarını kullanarak eşzamanlı yüz tanıma, yer işaretlerinin yerelleştirilmesi, poz tahmini ve cinsiyet tanıma için bir algoritma sunan bir diğer çalışmada ise HyperFace adı verilen bir yöntem önerilmiştir. $\mathrm{Bu}$ önerilen yöntem, derin bir CNN'nin orta katmanlarını, ayrı bir CNN ve ardından kaynaştırılmış özellikler üzerinde çalışan çok görevli bir öğrenme algoritması kullanarak birleştirmektedir. Bireysel performanslarını artıran görevler arasındaki sinerjiden yararlanır. Ek olarak, iki HyperFace çeşidi önerilmektedir: İlki, ResNet-101 modelini temel alan ve performansta önemli bir gelişme sağlayan HyperFace-ResNet ve diğeri ise bölge önerileri oluşturmak için yüksek geri çağırma hızlı yüz detektörü kullanan Hızlı HyperFace ile algoritma hızının artırılmasıdır [8]. Filtrelenmemiş yüzlerin yaş ve cinsiyet tahminini yapan çalışmada "vahşi" şartlarda zorlu olarak elde edilen yüz görüntülerinden yaş ve cinsiyet gibi yüz özelliklerinin tahmini ile ilgilidir. Sistemin yüz özellik tahmini için SVM yaklaşımı kullanılmıştır ve derin inanç ağlarıyla öğrenme tekniklerinden esinlenilmiştir [9].

$\mathrm{Bu}$ çalışmanın gerçekleştirilmesinde derin öğrenme algoritmalarından ve kütüphanelerinden faydalanılmıştır. Ubuntu işletim sistemi üzerinde python dili kullanılarak oluşturulan modellerin mimari yapısı, kütüphanelerin işlevleri ve derin öğrenme modelleri hakkında bilgilerden bahsedilmiştir.

\subsection{Derin Öğrenme Mimarisi}

Derin öğrenme mimarisinde yer alan 6 mimari yapı tartışılmaktadır. Bu yapılardan ilki olan, "Konvolüsyonel Sinir Ağları" mimarisi bilgisayarlı görme görevlerinde etkili ve bu çalışmanın modellenmelerinde ayrıntılı kullanılan bir mimaridir. CNN, derin öğrenme kavramına ait temel mimari yapısıdır. İlk CNN 1988 yılında Yann Le Cun tarafından oluşturulmuştur. 1998'lere kadar sürekli geliştirilen Le Net ilk CNN mimarisidir [10]. CNN'ler görüntüleri girdi olarak almak için tasarlanmış yapılardır ve bilgisayarlı görmede etkili bir şekilde kullanılmaktadır. $\mathrm{CNN}$, bir veya birden çok konvolüsyonel katman ve standart çok katmanlı bir sinir ağı gibi bir veya daha fazla tamamen bağlı katmanlardan oluşmaktadır [11]. Bir CNN'yi oluşturan katmanlardan aşağıda daha detaylı bahsedilmiştir. $\mathrm{Bu}$ katmanlar; Giriş Katmanı, Konvolüsyon Katmanı, Düzleştirilmiş Doğrusal Birim Katmanı, Havuzlama Katmanı, Tam Bağlantılı Katman, DropOut Katmanı ve Sinıflandırma Katmanı'dır. Çalışmanın geliştirilmesinde seçilen mimari yapı da CNN'dir.

Diğer derin öğrenme mimari yapıları hakkında kısa bilgiler verilmiştir. Bu mimari yapılardan biri olan "Tekrarlayan Sinir Ağları"; birimler arası verilerin yönlendirilmiş bir döngü oluşturduğu yapay sinir ağıdır. Tekrarlayan sinir ağları, görüntü tanımlayıcıları kullanmak için diğer mimarilerle birlikte kullanılmaktadır. "Uzun-Kısa Vadeli Hafıza Ağları" mimarisi; değerleri rastgele aralıklarla hatırlayan bir tekrarlayan sinir ağı mimarisidir. Bu mimari yapısı, konuşma/metin işleme çalışmalarında kullanıldığında iyi sonuçlar vermektedir. "Sınırlı Boltzman Makineleri"; girdi seti üzerinde olasılık dağılımlarını öğrenebilen görünür katman ve gizli katman olmak üzere 2 katmandan oluşan bir yapay sinir ağ yapısıdır. Sınırlı Boltzman Makineleri; sınıflandırma, özellik öğrenimi ve modelleme için uygun bir ağ olarak bilinir. "Derin İnanç Ağları" yapısı; Sınırlı Boltzman Makineleri'nin yığını ve oto kodlayıcılarla bileşimi olarak görülür. Derin İnanç Ağları, görüntü tanıma uygulamalarında kullanılmaktadır. "Derin Oto Kodlayıcılar" mimari yapısı ise; denetimsiz öğrenme için ve verinin üretken modellerini öğrenmek için kullanılan, girdi katmanı verilerini, çıktı katmanına kopyalayan bir yapıdır [12].

\subsection{Derin Öğrenme Kütüphaneleri}

Makine öğrenmesi ve derin öğrenme için çeşitli üniversiteler ve şirketlerce geliştirilmiş, farklı özelliklere sahip ve derin öğrenme çalışmalarını pratikleştirip kolaylaştıran birçok hazır kütüphane ve API'lar (Application Programming Interface-Uygulama Programlama Arayüzü) bulunmaktadır. 
Derin öğrenme yapısında çok sayıda kütüphane bulundurmaktadır. Çalışılacak konuya göre uygun kütüphanelerin bilgisayara kurulması gerekmektedir. Derin öğrenmede yapılacak uygulamayı basitleştirmeyi sağlayan kütüphaneler, derin öğrenme için büyük önem taşımaktadır. Bu kütüphanelerin her biri farklı işleve sahiptir. Python programlama dilinde, bir düzineden fazla derin öğrenme kütüphanesi mevcuttur. Çalışma için kullanılan kütüphaneler ise Keras ve TensorFlow'dur.

Python programlama dili ile kullanabilecek derin öğrenme kütüphanelerinin bazıları hakkında bilgi amaçlı bir tablo oluşturulmuştur. Theano, TensorFlow, Caffe, Keras, Mxnet, Pylearn2, Lasagne, Torch, Covnetjs, Sci-Kit Learn, Deeplearning4j, Apache Spark yoğun olarak kullanılan kütüphanelerden bazılarıdır. Tablo 1' de temel derin öğrenme kütüphaneleri listelenmiştir [12].

Tablo 1 Derin Öğrenme Kütüphaneleri

\begin{tabular}{|l|l|l|l|}
\hline Kütüphane Adı & Dili & Geliştiricisi & İşlevi \\
\hline Theano & Python & MILA Lab & $\begin{array}{l}\text { Çok boyutlu diziler dâhil, matematik ifadeleri etkili bir } \\
\text { şekilde tanımlamayı, en iyilemeyi ve değerlendirmeyi } \\
\text { sağlayan bir Python kütüphanesidir. }\end{array}$ \\
\hline TensorFlow & Python & Google & $\begin{array}{l}\text { Veri akışı grafikleriyle verimli sayısal hesaplamalara olanak } \\
\text { tanımaktadır. }\end{array}$ \\
\hline Caffe & Python & BVLC & $\begin{array}{l}\text { Caffe derin öğrenme yapısı hızlı ve modüler olacak şekilde } \\
\text { tasarlanmıştır. Model ve optimizasyonlar kodlama } \\
\text { yapılmaksızınayar dosyası üzerinden yapılabilmektedir. }\end{array}$ \\
\hline Keras & Python & Google & $\begin{array}{l}\text { Keras kütüphanesi Tensorflow ve Theano'ya üst katman } \\
\text { olarak yazılmış, daha kolay model geliştirmeyi sağlayan bir } \\
\text { Python kütüphanesidir. }\end{array}$ \\
\hline Mxnet & Amthon & $\begin{array}{l}\text { Keras gibi yüksek seviye kütüphanedir, bir polyglot (çok } \\
\text { dilli) olmasından dolayı, farklı dillerde model paylaşan } \\
\text { ekipler için harika çözümler sunmaktadır. Diğer bir avantaji } \\
\text { ise dağttılmış bilgi işlemini desteklemesidir. }\end{array}$ \\
\hline
\end{tabular}

\subsection{Derin Öğrenme Modelleri}

ImageNet model yarışmasını kazanan CNN modelleri; Alex Net, Le Net, ZF Net, VGG-16, GoogLe Net, Microsoft RestNet gibi modeller başta olmak üzere sıralanabilir. Bu modeller derin öğrenmeyi anlamada ve geliştirmede önemli bir yer edinmektedir. Bu sebeple modeller oldukça önemlidir.

Le Net; 1998 yılında yayınlanmış ve ilk başarılı sonucu veren CNN modelidir. Yan Le Cun ve ekibi tarafından posta numaraları, banka çekleri üzerindeki sayıların okunması amacıyla hazırlanmıştır.

Alex Net; dünya çapında derin öğrenmenin duyulmasını sağlayan 2012 yılı ImageNet yarışmasını kazanmış ve Krizhevsky, Sutskever ve Hinton tarafından geliştirilmiş bir modeldir. Birbirini takip eden konvolüsyon katmanları ve ortaklama katmanları ile toplam 25 katmandan meydana gelmektedir. 
Bilgisayarlı nesne tanımlama doğruluk oranını \%10,8 iyileştirerek \%83,6 yapmıştır. Şekil 2'de Alex Net mimari yapisı mevcuttur $[13,14]$.

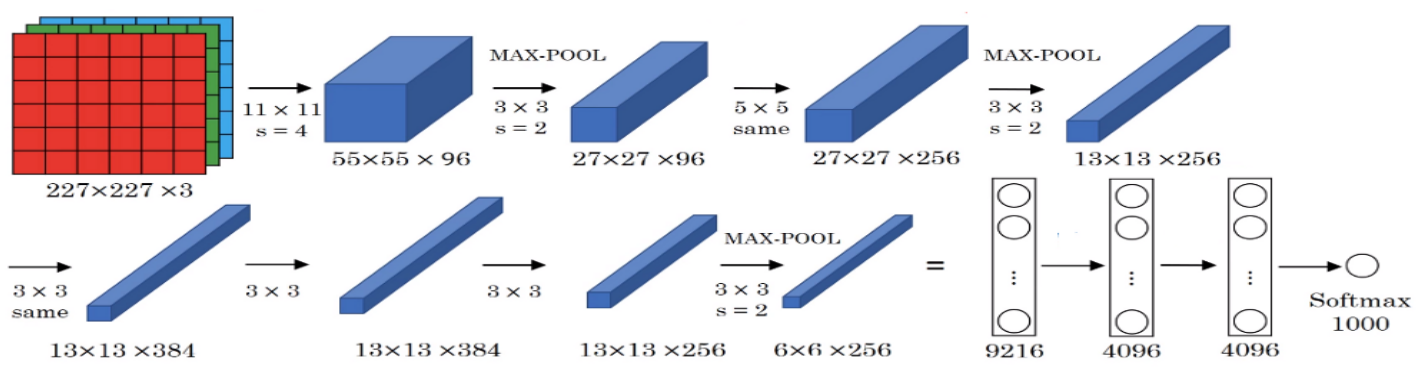

ZF Net; 2013 yılı ImageNet yarışmasını kazanan, Alex Net mimarisinin geliştirilmiş hali olan modeldir. Nesne tanıma hata oranını $\% 4,2$ daha iyileştirmiş ve $\% 11,2$ ye düşürmüştür.

VGG-16; 2014 yılı ILSVRC yarışmasında, daha iyi sonuçlar için geliştirilmiş basit bir ağ modeli olan VGG-16'yı daha önceki modellerden ayıran en önemli fark, ikili ya da üçlü konvolüsyon katmanlarını ortaklama katmanlarının izlemesidir. Şekil 3'de VGG-16 mimari yapısı verilmiştir. Bu model, 13 konvolüsyon katmanı, 3 tam bağlı katman, havuzlama, Relu, Dropout ve Softmax katmanlarıla birlikte toplamda 41 katmandan oluşmaktadır [13].
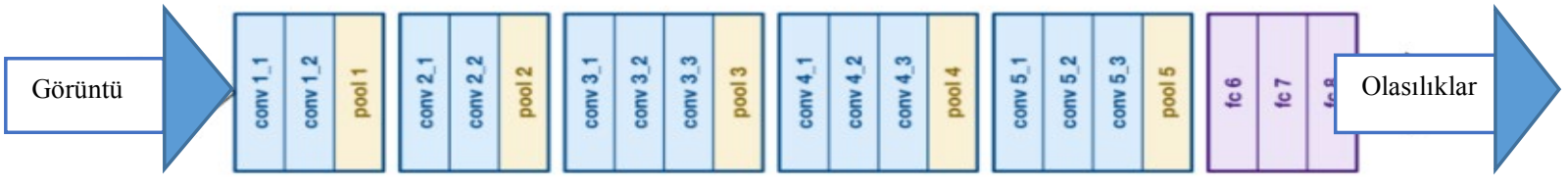

\section{Şekil 3 VGG-16 Mimari Yapısı}

Google Net; ImageNet 2014 yılı yarışmasının kazanmış olan ve Inception modüllerinin birleşiminden oluşan model karmaşık bir yapıya sahiptir. \%5,7 hata oranına sahip olan model, veri kümelerinde başarılı sonuçlar vermiştir.

Microsoft Rest Net; Tüm mimari yapılardan daha derin olarak tasarlanan model, 2015 y1lı ImageNet yarışması kazananı olmuştur. 34 katmanlı ilk ağ olan yapı residual bloklardan oluşmaktadır [14].

\section{Uygulama Çalışması}

Fotoğraflardan derin öğrenme ile cinsiyet tahmini yapabilmek için veri seti olarak Vikipedi fotoğraflarından derlenen 3170 görüntülük dosya oluşturulmuştur. Veri seti içindeki resimler cinsiyetlerine ve yaşlarına göre etiketlendirilmiştir. Kadın ve erkek olmak üzere 2 sınıf oluşturulmuştur. Her biri veri görüntüsü yaş ve cinsiyet bilgisine göre etiketlendirilmiştir. Eğitim veri seti için 3170 görüntü, test veri seti için ise toplam görüntü içinden rasgele seçilen 318 görüntü kullanılmıştır. Uygulama, Ubuntu işletim sistemi üzerinde Python diliyle yazılmıştır. Sınıflandırma için derin öğrenme modellerinden Alex Net ve optimize edilmiş VGG-16 gibi derin öğrenme algoritmaları kullanılmıştır. Bütün algoritmalar 'PyCharm' Python geliştirme ortamında çalıştırılmışırır. Yeni geliştirilen bir derin öğrenme modeli ile Alex Net ve optimize edilmiş VGG-16 parametrelerinin kıyaslaması yapılmıştır. 
Yeni geliştirilen model 14 konvolüsyon katmanı ve 7 havuzlama katmanından ve 3 tam bağlantılı katmandan oluşmaktadır. Toplam parametre sayısı 46.197.314'tür. SSekil 4 ile modelin katman yapısı detaylı olarak ifade edilmiştir.

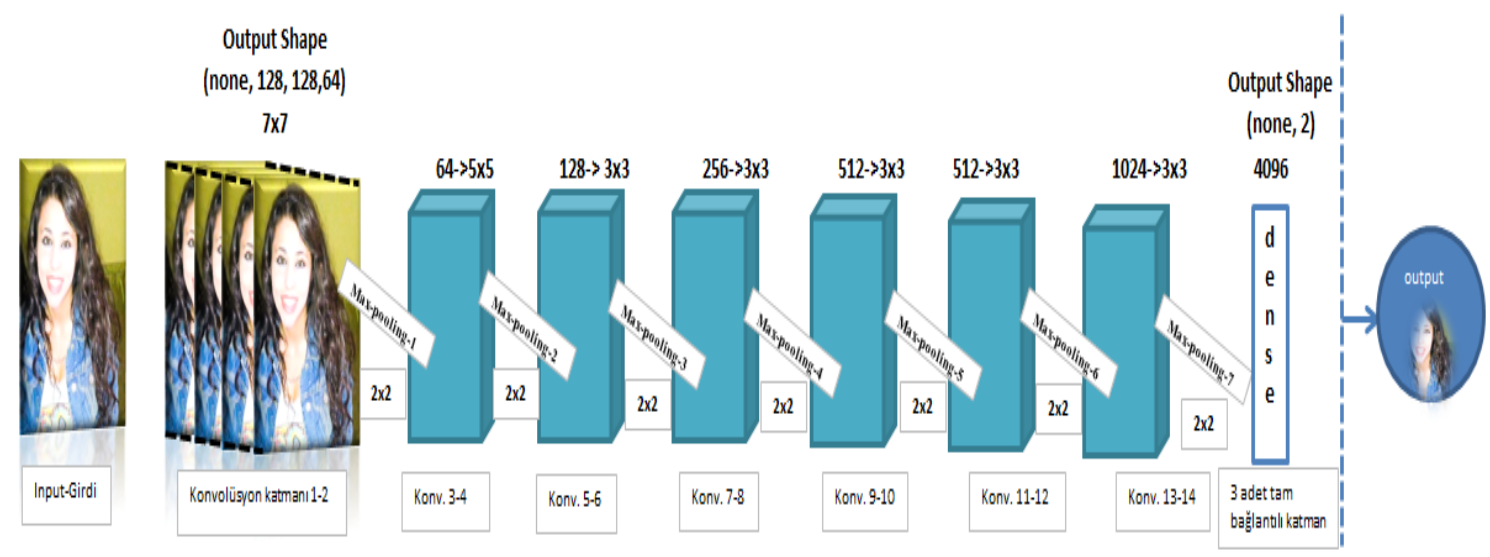

Şekil 4 Yeni Model Mimari Yapısı

Yeni modelin, karşılaştırma yapılan algoritmalardan farkını gösteren bilgiler tablo 2'de detaylı olarak gösterilmiştir. Tablodan yapılan incelemeler sonucu görüldüğü gibi yeni model, Alex Net ve VGG-16 modellerinden farklı bir mimariye sahip olmakla birlikte, başarım değerlendirmesi olarak da Alex Net ve VGG-16 modellerinin arasında bir sonuç vermektedir. İşlem süresi bir kıyaslama kriteri olarak alındığında en uzun süreli çalışan modelin yeni geliştirilen model olduğu gözlenmiştir. Yüz tanımada kenarlık çıkarma işlevi için havuzlama katmanı kullanılmaktadır. Havuzlama katmanının, ayrıntıları alırken bilgi kaybına sebep olması ihtimali vardır. Yeni modelin VGG-16'dan farklı olarak, Alex Net gibi DroupOut katmanına sahip olmadığı da görülmektedir. DropOut katmanı, ağ içindeki bazı bağlantıların kaldırılmasıyla eğitim performansını artırmaktadır. Öğrenememe ve ezberleme problemlerine çözüm için kullanılmaktadır. Relu aktivasyon fonksiyonu da aynı problemlere çözüm için modellerde bulunmaktadır [15]. Uygulama bölümündeki bütün modeller için keras, tensorflow ve matplotlib kütüphaneleri kullanılmıştır.

Tablo 2 Modellerin Mimari Yapılarının Karşılaştırılması

\begin{tabular}{|l|l|l|l|l|l|l|l|}
\hline $\begin{array}{l}\text { Modeller ve } \\
\text { Mimari } \\
\text { Bilgileri }\end{array}$ & $\begin{array}{l}\text { Konvolüsyon } \\
\text { Katmanı } \\
\text { sayısı }\end{array}$ & $\begin{array}{l}\text { Havuzlama } \\
\text { Katmanı } \\
\text { sayısı }\end{array}$ & $\begin{array}{l}\text { Relu } \\
\text { Katmanı } \\
\text { Sayısı }\end{array}$ & $\begin{array}{l}\text { Dense } \\
\text { Katmanı } \\
\text { Sayısı }\end{array}$ & $\begin{array}{l}\text { Flatten } \\
\text { Katmanı } \\
\text { Sayısı }\end{array}$ & $\begin{array}{l}\text { Darametre } \\
\text { Sayısı }\end{array}$ & $\begin{array}{l}\text { Katmanı } \\
\text { Durumu }\end{array}$ \\
\hline Alex Net & 5 & 3 & 7 & 3 & 1 & 26.004 .894 & Yok \\
\hline Yeni Model & 14 & 7 & 16 & 3 & 1 & 46.197 .314 & Yok \\
\hline VGG-16 & 13 & 5 & 14 & 2 & 1 & 23.129 .945 & Var \\
\hline
\end{tabular}

Hazırlanan veri setinin üç farklı modelde çalıştırılması ile ortaya çıkan sonuçlar tablo 3'de gösterilmiştir. Veri setinin uygulama içinde en uyumlu olduğu modeli seçmek üzere tablo incelenmiştir. Model tasarlanırken mini-batch parametresi olarak belirlenen değer; modelin aynı anda kaç veriyi işleyeceğini ifade etmektedir [16]. Epoch sayısı ise modelin kaç iterasyon çalışacağını saptayan bir hiper parametredir. Bütün modeller için aynı mini batch sayısı ve epoch sayısı belirlenmesinin nedeni modellerin başarımlarının karşılaştırmasının, model algoritmasına göre yapılmasını sağlamaktır. Mini batch ve epoch sayısını artırma ya da azaltma gibi işlemlerin başarım yüzdesini değiştirebileceği düşünülmektedir. Tablo 3'de çalışma hakkında detaylı bilgiler hakkında veriler mevcuttur. Modelin başarıma etkisini, inceleme yaparak daha iyi anlamayı amaçlayan çalışma veri sonuçlarıyla da bu etkinin sayısal olarak 
ifadesini açık bir şekilde ifade etmiştir. Cinsiyet ve yaş tahminleri için ayrı olarak değerlendirmeler yapılmıştır.

Tablo 3 Hazırlanan Veri Seti ile Çalıştırılan Model Sonuçları

\begin{tabular}{|c|c|c|c|c|c|c|}
\hline \multicolumn{7}{|c|}{ CINSIYET TAHMINLEME İÇIN ÇALISSTIRILAN SONUÇLAR } \\
\hline & Model Türü & Katman Sayısı & Mini Batch Sayısı & Epoch Sayısı & Optimizer & \begin{tabular}{|l|l|} 
En iyi \\
Başarım \\
\%' si \\
\end{tabular} \\
\hline \multirow{3}{*}{$\sum_{0}^{n}$} & Alex Net & 25 & 32 & 150 & SGD & $\% 65,63$ \\
\hline & Yeni Model & 41 & 32 & 150 & SGD & $\% 72,20$ \\
\hline & VGG-16 & 41 & 32 & 150 & SGD & $\% 99,41$ \\
\hline
\end{tabular}

Sonuçlardan görüldüğü üzere en iyi doğruluk yüzdesini, VGG-16 modeli vermektedir. VGG-16 modelinin 150 iterasyon çalıştırılması sonucu ortaya çıkan başarım ve kayıp değer grafikleri sonuç kısmındaki şekil 5'te gösterilmiştir.

CPU ile çalışmanın uzun sürmesi nedeniyle, eğitimler için GPU destekli bilgisayarlar tercih edilmiştir. Minibatch sayısı artırmanın ve epoch sayısı artırmanın doğruluk yüzdesini artırırken süreyi uzattığı tespit edilmiştir.

\section{Sonuç ve Öneriler}

Derin öğrenme algoritmalarını kullanarak cinsiyet tahmini yapan bir uygulama örneği olarak yapılan çalışmada, Vikipedi görüntülerinden derlenen bir veri setinin modellerdeki performansı kıyaslanmıştır. Bu kıyaslamada en iyi performansı VGG-16 modelinin verdiği gözlemlenmiştir. Geliştirilen modelin ise veri setine uyumunun, Alex Net modelinden daha iyi ve VGG-16 modelinden ise daha kötü bir sonuç verdiği belirlenmiştir. $\mathrm{Bu}$ yüzden, modelin daha fazla denemelerle geliştirilmesi gerektiği saptanmıştır. Alex Net en iyi başarım \%65,62 bir derin öğrenme çalışması için başarılı bir sonuç sayılmazken, yeni modelin \%72,20 olan başarımı geliştirilmeye açık bir model olduğunu göstermektedir. Veri çeşitliliği, veri sayısı artırımı, minibatch artırımı, optimizer farklılaştırma, katmanları artırma gibi işlemlerin denenmesi devam edilerek daha iyi sonuçlar bulunması hedeflenmektedir. Grafiksel olarak öğrenmenin gerçekleştiği ve ezberlemenin olmadığı en iyi model olan VGG-16'nın incelenmesi durumunda, grafiksel sonuçlar veri seti ve model uyumunu belirgin bir biçimde göstermektedir. Şekil 5'de en iyi sonucu veren modelin başarım ve kayıp grafikleri bulunmaktadır.
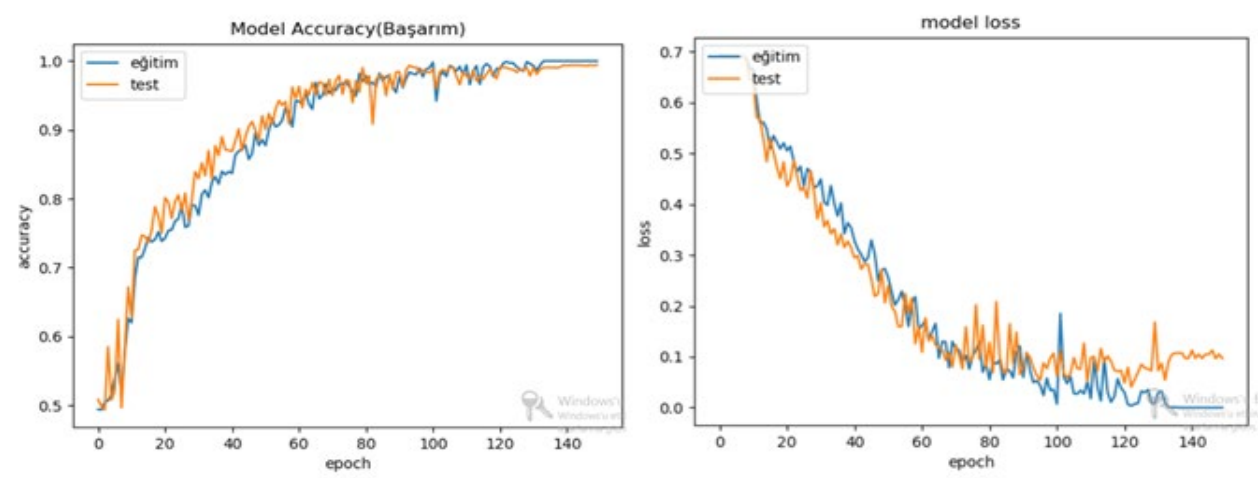

Şekil 5 Çalıştırılan VGG-16 Modeli Başarım ve Kayıp Grafiği 
VGG-16 modeli ile uyumlu olduğu görülen veri setine göre, 150 iterasyon ile çalışan modelin $\% 99,41$ başarım elde ettiği tespit edilmiştir. 140 iterasyondan sonra öğrenmenin doygunluğa ulaştığı ve \%99,41 de kaldığı, grafikler incelendiğinde fark edilmektedir. Bu uygulama sonucunda elde edilen VGG-16 başarım ve kayıp grafiklerindeki eğriler analiz edildiğinde, amaçlanan öğrenmenin gerçekleştirildiği görülmektedir.

\section{Kaynakça}

[1] https://www.log.com.tr/tek-fotograftan-yas-tahmini-yapan-siteye-buyuk-ilgi/, [Erişim tarihi: 12 Ocak, 2019].

[2] https://www.teknoblog.com/xiaomi-mi-6-on-kamera-tahmin/, [Erişim tarihi: 12 Ocak 2019].

[3] Rasmus Rothe, Radu Timofte, Luc Van Gool; "DEX: Deep EXpectation of Apparent Age From a single image", ICCV, 2015.

[4] Kwang Gi Kim; "Deep Learning”; PhD, Biomedical Engineering Branch Division of Precision Medicine and Cancer Informatics, National Cancer Center, Goyang, Korea, 2016.

[5] Abdulkadir ŞEKER, Banu DİRİ, Hasan Hüseyin BALIK; "Derin Öğrenme Yöntemleri ve Uygulamaları Hakkında Bir İnceleme”, Gazi Mühendislik Bilimleri Dergisi, 2017.

[6] B.A. Golomb, D.T. Lawrance and T.J.Sejnowski; "Sexnet: A Neural Network Identifies Sex From Human Faces, In Neural Inform Processing System, 1991.

[7] Gil Levi and Tal Hassner; "Age and Gender Classification using Convolutional Neural Networks", Computer Vision Foundation, 2015.

[8] Rajeev Ranjan, Vishal M. Patel, Rama Chellappa; "HyperFace: A Deep Multi-Task Learning Framework for Face Detection, Landmark Localization, Pose Estimation, and Gender Recognition", IEEE Transactions on Pattern Analysis and Machine Intelligence, Volume: 41 , Issue: 1 , Jan. 1 2019, DOI: 10.1109/TPAMI.2017.2781233--- Page(s): 121 - 135, 08 December 2017.

[9] Eran Eidinger, Roee Enbar, Tal Hassner; “Age and Gender Estimation of Untifiltered Faces”, IEEE, 2013.

[10] Y. Le Cun et al.; "Handwritten digit recognition: applications of neural network chips and automatic learning,” IEEE Commun. Mag., Vol. 27, no. 11, pp. 41-46, Nov. 1989.

[11] Y. LeCun, Y. Bengio, and G. Hinton, “Deep learning,” Nature, Vol. 521, pp. 436-444, 2015.

[12]Abdulkadir ŞEKER, "Derin Öğrenme Yöntemleri ve Uygulamaları Hakkında Bir İnceleme", Doktora Semineri, YTÜ Bilgisayar Müh. Bölümü, İstanbul, 2017.

[13] Ferdi Doğan, İbrahim Türkoğlu; "Derin Öğrenme Algoritmalarının Yaprak Sınıflandırma Başarımlarının Karşılaştırılması”, Vol.1,ID. SAUCIS-1-2018, April 2018.

[14] Merve Ayyüce KIZRAK, Bülent BOLAT, "Derin Öğrenme ile Kalabalık Analizi Üzerine Detaylı Bir Araştırma, Literatür Makalesi/Review Article", Bilişim Teknolojileri Dergisi, cilt: 11, sayı: 3, Temmuz 2018.

[15] http://derindelimavi.blogspot.com/2015/11/derin-ogrenme-2.html, [Erişim Tarihi: 4 Mart 2019] 
Sakarya University Journal of Computer and Information Sciences

Gul Gunduz and Ismail Hakki Cedimoglu

[16] https://medium.com/deep-learning-turkiye/derin-ogrenme-uygulamalarinda-en-sik-kullanilanhiper-parametreler-ece8e9125c4, [Erişim Tarihi: 4 Mart 2019] 